\title{
Peran Stakeholders dalam Konservasi Penyu Belimbing di Pantai Peneluran Jamursba Medi Kabupaten Tambrauw Provinsi Papua Barat
}

Martha Yulita Yewen a, 1, I Made Bayu Ariwangsa a, 2

1julitayewen@gmail.com, 2bayu_ariwangsa@unud.ac.id

a Program Studi S1 Destinasi Pariwisata, Fakultas Pariwisata,Universitas Udayana, Jl. Dr. R. Goris, Denpasar, Bali 80232 Indonesia

\section{Abstract}

The conservation potential of Leatherback Sea Turtle in Jamursba Medi Spawning Beach is for ecotourism attraction. This research was conducted at PeneluranJamursbaMedi Beach. This research was conducted to find out the potential of Leatherback Sea Turtle at JamursbaMediSpawningBeach as ecotourism attraction in Tambrauw Regency and also to find out the form of cooperation of Stakeholders in the area of JamursbaMediSpawningBeach, Regency of Tambrauw, Province of West Papua. The type of data being used in this research was qualitative and quantitative with primary and secondary data source obtained through data sampling technique of depth interview observation, literature study with informant determination technique of purposive sampling and data analysis technique of descriptive qualitative. The result of research shows that in the area of Spawning Beach, Leatherback Sea Turtles have a potential to support tourism development in the form of natural, cultural and human. These three potencies are the assets to give contribution for tourism development and management of coastal park and has potential for ecotourism sector. So participation and active role of stakeholders namely Government, Population, and non-governmental organizations / WWF (World Wildlife Fund) is required for advancement and development in the area ofJamursbaMediSpawningBeach.

\section{Key words: Potency, Ecotourism Conservation, Stakeholder.}

\section{PENDAHULUAN}

Indonesia merupakan salah satu negara yang kaya akan budaya, keanekaragaman hayati flora dan fauna yang sangat berlimpah. Kekayaanbudaya flora dan fauna yang dimiliki tersebut merupakan salah satu daya tarik yang memiliki nilai ekonomis jika dapat dikombinasikan dan dikemasdenganbaik menjadi atraksi wisata maupun paket perjalanan yang menarik bagi wisatawan nusantara mapun mancanegara.

Laporan yang dikeluarkan World Tourism Organization (WTO) dalam Arida 2009mengungkapkan adanya beberapa kecendrungan dan perkembangan baru dalam dunia kepariwisataan yang mulai muncul pada tahun 1990-an denganadanya kecendrungan masyarakat global, regional dan nasional untuk kembali ke alam back tonature, sehingga minat masyarakat untuk berwisata ke tempat-tempat yang masih alami semakin meningkat. Minat tersebut merupakan factor pendorong bagi dikembangkannya pariwisata yang berorientasi padalingkungan alam karena motivasi wisatawan untuk mencari kehidupan dalam tata lingkungan yang berbeda, bagi wisatawan memiliki sifat petualang di alam bebas serta menambah wawasan dalam keaneka ragaman flora dan fauna.
Ekowisata merupakan wisata berbasis Islam yang berkelanjutan dengan focus pengalaman dan pendidikan tentang alam, di kelola dengan system pengelolaan tertentu dan memberi dampak negative paling rendah terhadap lingkungan tidak bersifat konsumtif dan berorientasi lokal (Fennel,1999:43)

Kegiatan ekowisata secara langsung maupun tidak langsung mengarahkan wisatawan untuk menghargai dan mencintai alam serta budaya lokal, sehingga dapat menumbuhkan kesadaran dan kepedulian para wisatawan untuk turut memelihara kelestarian alam. Kabupaten Tambrauw memiliki beberapa daya tarik wisata yang hampir sebagian meliputi kawasan konservasi baik hutan, laut maupun beberapa hewan endemik yang dilindungi dan dapat dijadikan sebagai potensi unggulan. Daya tarik wisata diantaranya Pantai Peneluran Jamursba Medi, Batu Rumah, dan Pantai Warmon sebagai habitat Penyu Belimbing Pulau Dua, kawasan Senopi sebagai populasi Burung Cenderawasih, Pulau Miosu, dan potensi wisata budaya lainnya yang berupa peninggalan sejarah, dan kehidupan masyarakat khas Papua yang unik, sebaran suku dengan pola hidup yang beanekaragam.

Kawasan Jamursba Medi terletak di Kabupaten Tambrauw Propinsi Papua Barat ditunjuk sebagai cagar alam dengan SK Menteri Pertanian Nomor: 820/Kpts/Um/11/1982 
tanggal 10 November 1982 dan SK Menteri Kehutanan namun menurut peta kawasan hutan dan perairan kawasan ini ditunjuk sebagai suaka margasatwa. Secara adminstrasi masuk dalam wilayah Distrik Abun Kabupaten Tambrauw, Kawasan ini merupakan kawasan peneluran penyu belimbing (Dermochelys coriacea) yang cukup potensial.

Melihat potensi tersebut maka penelitian ini penting dilakukan untuk mengetahui bentuk kerjasama stakeholders dalam hal ini pemerintah daerah, masyarakat lokal dan swasta dalam pengelolaan kawasan konservasi pantai peneluran Jamursba Medi Kabupaten Tambrauw, hingga potetnsi penyu tetap terjaga dan lestari dan dapat memberikan manfaat yang baik terhadap kegiatan ekonomi bagi masyarakat lokal di Kabupaten Tambrauw

\section{TINJAUAN PUSTAKA}

Penelitian sebelumnya tentang peranan WWF di Indonesia oleh Hartati (2002) dengan berjudul "Perananan WWF Wallacea terhadap Pelestarian Lingkungan untuk Pengelolaan Penyu Laut di Indonesia yang menjelaskan bahwa terjadi penurunan populasi penyu laut secara tajam dari tahun ke tahun di Indonesia terkait dengan dijadikannya penyu laut sebagai komoditas perdagangan yang menjanjikan keuntungan yang menggiurkan. Sebagian besar perdagangan penyu dari seluruh komoditas penyu Indonesia didistribusikan di Bali. Karena pusat perdagangan penyu terkosentrasi di Pulau ini, maka Bali menjadi tempat utama untuk pelaksanaan program-program WWF wallacea.

Selanjutnya penelitian dilakukan oleh Wulandari (2002) dengan judul "Pengembangan potensi kawasan air panas Gunung Pancar di Desa Karang Tengah Kecamatan Babakan Madang Kabupaten Bogor. Dalam penelitian ini peneliti mengkaji tentang potensia yang dimiliki lokasi penelitian dan daya tarik serta pengembangan kawasan air imbing panas gunung Pancar sebagai ekowisata ditunjang dari segala sarana dan prasarana yang ada.

\section{METODE}

Penelitian ini dilakukan di Pantai Peneluran Penyu Belimbing Desa Saubeba Distrik Abun Kabupaten Tambrauw Provinsi Papua Barat, kawasan ini selain memiliki potensi Penyu Belimbing juga memiliki keindahan alam sekitar pantai dengan pasir putih dan kawasan hutan sehingga penting peran Stakeholder dalam pengembangan kawasan Pantai Peneluran Jamursba Medi yang bertujuan meningkatkan ekonomi masyarakat lokal.

Bentuk kerja sama stakeholder dalam pengelolaan kawasan Konsevasi Penyu Belimbing di Pantai Peneluran Jamursba Medi Kabupaten Tambrauw Papua Barat. Bentuk kerja sama yang dimaksud adalah terdiri dari tiga pilar utama yaitu masyarakat yang ada di destinasi sebagai pemilik dari sumber daya yang merupakan modal pariwisata, swasta yang merupakan asosiasi usaha pariwisata para pengusaha dan juga LSM, pemerintah yang sebagai regulasi atau fasilitator yang membuat aturan berupa produk hukum dan lain sebagainya.

Jenis data yang digunakan dalam penelitian ini adalah data kualitatif dan data kuantitatif yanag dimaksud adalah : tentang gambaran umum Pantai Peneluran Penyu Bellimbing di Kabupaten Tambrauw, potensi yang dimiliki pelibatan masyarakat lokal dan bentuk kerja sama antar Pemerintah Daerah Masyarakat Lokal dan WWF dan implementasi program dan bentuk kerja sama dalam pengembangan potensi Penyu Belimbing sedangkan sumber data yang digunakan dalam penelitian ini adalah data yang diperoleh secara langsung di lokasi penelitian berupa informasih dari informan yaitu Kepala Bidang Promosi Dinas Pariwisata, Kepala Distrik Abun, Pimpinana WWF dan Tokoh Kunci Masyarakat Lokal melalui wawancara mendalam dan observasi. Data primer meliputi program kerja sama antar pengelola kawasan yatitu stakeholder pemerintah masyarakat lokal dan WWF dan data sekunder yang dimaksud dalam penelitian ini adalah literature atau buku-buku, studi kepustakaan, dokumen berpa tulisan-tulisan dan profil kawasan Pantai Peneluran Penyu Belimbing oleh WWF. sedangkan teknik pengumpulan data yang digunakan dalam penelitian ini adalah observasi wawancara mendalam dan studi kepustakaan. Dalam menentukan informan yang akan dijadikan narasumber, teknik penentuan informan yang digunakan adalah purposive sampling, yaitu peneliti menentukan informan yang dapat memberikan informasih sesuai dengan tujuan 
dan masalah yang akan diteliti, sebagaimanadikemukaan oleh Kusmayadi dan Sugiarto (2000)

\section{HASIL DAN PEMBAHASAN}

Pantai peneluran Penyu Belimbing adalah salah satu kawasan yang terletak di Desa Saubeba Distrik Abun Kabupaten Tambrauw Provinsi Papua Barat. Sejaka da kehidupaan masyarakat telah mengetahui kawasan ini sebagai tempat bertelurnya penyu belimbing yang awalnya telur penyu tersebut di jadikan sebagai konsumsi dan mata pencaharian masyarakat lokal di sekitar kawasan.

Sejarah kawasan sejak Tahun 1982 upaya konservasi telah dilakukan mulai dari pengamatan kawasan hingga kegiatan pengelolaan yang melibatkan masyarakat. Hingga pada saat ini ada tiga lembaga yang bekerja dalam pelestarian penyu yaiu lembaga swadaya masyarakat WWF dan YPLI/Yayasan PenyuLaut Indonesia, Perguruan Tinggi Universitas Papua dan Pemerintah Daerah Kabupaten Tambrauw. Tiga lembaga ini berada dalam koordinasi BBKDA Papua Barat. Suaka marga satwa Jamursba Medi merupakan kawasan untuk perlindungan pantai peneluran Penyu Belimbing. Kawasan Pantai Peneluran cukup panjang dan luas, lokasi utama penyu bertelur yaitu di sebelah barat pantai Suaka Marga Satwa Jamursba Medi dan di sebelah timur Pantai Warmon.

Jenis penyu yang terdapat di taman pesisir Jamursba Medi adalah Penyu Belimbing, Penyu Lekang, Penyu Sisik, Penyu Hijau. Penyu Belimbing merupakan penyu yang terbesar dengan ukuran panjang badan mencapai 2,75 meter dan bobot 600-900 kilogram, sedangkan penyu terkecil adalah Penyu Lekang dengan bobot sekitar 50 kilogram. Penyu Belimbing diketahui memiliki kisaran pergerakan yang paling luas dibandingkan dengan penyu reptillainnya, Penyu Belimbing bermigrasi melintasi Samudera Pasifik bahkan Atlantik. Penyu Belimbing yang bertelur di Amerika Tengah dan Meksiko diketahui bermigrasi kearah selatan menuju perairan hangat tropis Paifik Selatan, studi yang dilakukan terhadap 9 ekor Penyu Belimbing pasca bertelur di Pantai Peneluran Jamursba Medi menunjukan bahwa penyu-penyu tersebut bergerak menuju berbagai perairan tropis yaitu ke arah Filipina dan Malaysia, perairan di Jepang hingga menyebrangi Equatorial Pasifik ke Perairan hangat Amerika Utara. Namun keunikan Penyu Belimbing ketika ingin bertelur ia akan kembali bertelur disepanjang Pantai Peneluran Jamursba Medi pada tiap tahun, Bulan Mei, Juni, dan Agustus bisa dijumpai di sepanjang Pantai Peneluran Jamursba Medi.

\section{a. Bentuk KerjaSama Stakeholder}

Dalam system pengelolaan Kawasan Konservasi Pantai Peneluran Jamursba Medi ada lembaga yang berperan dalam rangka melestarikan habitat penyu dan juga kelestarian alam sekitar dan masyarakat lokal yang dilakukan oleh Pemerintah, Masyarakat dan WWF. Upaya-upaya bahkan bentuk kerja sama antar stakeholder terus dilakukan dengan berbagai upaya agar Penguatan kapasitas kelembagaan Taman Pesisir tetap terjaga secara bersama sehingga pelestarian habitat penyu belimbing serta kawasan hutan dan biota alam lainnya tetap terjaga. Tiga lembaga yang ikut terlibat bekerja dalam pelestarian penyu, yaitu lembaga swadaya masyarakat (WWF dan YPLI/Yayasan Penyu Laut Indonesia), Perguruan Tinggi Universitas Negeri Papua dan Pemerintah Daerah Tambrauw tiga lembaga ini berada dalam koordinasi BBKSDA Papua barat. Bentuk peran serta yang dilakukan stakeholder Pemerintah, Masyarakat Lokal dan WWF antara lain:

1. Pemerintah

Membuat regulasi berupa aturan dan produk hukum tentang kawasan Pantai Peneluran Jamursba Medi baik dalam kegiatan konservasi maupun kepariwisataan dan Mnyediakan dan membangun infrastruktur transportasi darat, laut dan pra sarana pendukung lainnya

2. Masyarakat

Ikut mendukung program pemerintah daerah bahkan WWF serta berpartisipasi menjaga kelestarian kawasan Pantai Peneluran Jamursba Medi dari kerusakan alam yang disengaja bahkan tidak disengaja

3. WWF

Melakukan pemantauan perlindugan dan pengawasan di Pantai Peneluran secara partisipatif dan memberikan pendidikan lingkungan hidup kepada masyarakat lokal.

\section{b. Peran Masyarakat Lokal}

Masyarakat lokal telah mengetahui tentang Penyu Belimbing sejak dahulu kala secara turun temurun yang berasal dari cerita nenek 
moyang sebagai lambang kemakmuran. Penyu ini merupakan hewan asli daerah hinga cara melestarikannya mengunakan kearifan lokal yang dikelola oleh masyarakat setempat, secara turun temurun untuk menyaksikan Penyu Belimbing mendarat ke bibir pantai/ laut setiap bulan Mei, Juni dan Aggustus adalah melalui upacara adat pemanggilan.

Dengan upacara inilah masyarakat memiliki hubungan emosional terhadap Penyu Belimbing sehingga tetap lestari. Masyarakat sangat melarang tindakan pembunuhan terhadap Penyu Belimbing di mana sebelum berdirinya Kabupaten Tambrauw, masyarakat lokal menjadikan telur penyu sebagai sumber konsumsi utama, saat itu telur Penyu Belimbing sangat berlimpah sehingga dapat memenuhi kebutuhan masyarakat lokal.

Penyu Belimbing bagi masyarakat lokal sangat berperan penting dalam memelihara kelangsungan ekosistem pesisir dan laut, hewan ini juga membersihkan laut dari uburubur sehingga masyarakat dapat mengunakan sepanjang pantai untuk mandi dan aktifitas lainnya kehadiran Penyu Belimbing sangat positif bagi masyarakat. Masyarakat lokal menginginkan adanya pengembangan pariwisata di kawasan pantai peneluran sehingga dapat meningkatkan ekonomi masyarakat setempat.

Masyarakat sangat mendukung pelestarian penyu bentuk partisipasi masyarakat pada dasarnya suda ada sejak adanya kehidupan.Seperti yang disampaikan pada saat wawancara bersama salah satu tokoh pemuda masyarakat Yohanes Sundoy beberapa hal yang disampaikan adalah" ini kawasan peneluran terbesar di dunia kalau tempat yang penyu jalan-jalan cari makan seperti di pulau keibagi saya tidak terlalu penting, selama ini kami masyarakat sendiri yang berjuang kami terpaksa memberhentikan berbagai aktifitas seperti perusahaan Tambang dan Perusahaan Kayu, terus apakah ini cuma jadi slogan saja untuk kita bicara munculkan di internet kita heboh-hebokan dengan berkampanye dan lainlain tapi ternyata kita tidak mampu untuk melindungi kawasan kita sendiri jadi bagi saya kita harus benahi instansi terkait salah satunya Dinas Pariwisata secara khusus untuk kegiatan kepariwisataan kedua teman-teman yang sekarang suda menulis tentang hal ini harus terus bicara untuk kawasan ini jangan hanya menulis untuk dapat gelar saja.

Faktor lemahnya kerja sama karena tidak adanya program yang menyentuh kepada masyarakat, ada pun faktor keberlangsungan ekonomi terkait dengan pendistribusian hasil kebun/pertanian ke kota yang selalu menjadi kendala utama yaitu penyediaan sarana transportasi umum yang sangat minim bahkan tidak ada sehingga masyarakat sulit untuk melakukan transaksi ekonomi ke kota, akibatnya kehidupan ketergantungan kepada alam masih terus terjadihingga pemburuan liar termasuk pengambilan telur penyu yang dilakukan sebagai bahan konsumsi untuk menunjang kebutuhan hidup.

Dengan adanya pembentukan Forum Kolaborasi di tingkat Kabupaten maka Untuk mempermudah komunikasi dan koordinasi di tingkat masyarakat kampung. Pada bulan November 2014 telah dibentuk tim 15 yang merupakan perwakilan masyarakat dan dipilih sebanyak lima orang dari tiga kampung, yaitu Subeba, Warmandi dan Wauw target yang ingin dicapai oleh forum kolaborasi dan tim 15 adalah tahun 2019 pengelolaan perlindungan penyu belimbing dan pantai peneluran Jamursba Medi dan Warmon bisa dilakukan secara mandiri dan berkelanjutan oleh masyarakat lokal, bersama Pemerintah Kabupaten Tambrauw dan Para pihak lain, sehingga mampu memberikan kontribusi terhadap peningkatan kesejahteraan masyarakat dan kelestarian Penyu Belimbing.

\section{c. PeranSwasta/WWF}

Dalam pelestarian penyu belimbing selain peran pemerintah juga ada peran organisasi Word Wildlife Found Indonesia (WWF) merupakan organisasi non pemerintah yaitu Swadaya Masyarakat yang berasal dari Swiss. Peran yang dilakukan WWF dalam waktu 4 tahun ini yaitu dari tahun 2012 hingga tahun 2015 telah berupaya melakukan perlindungan dan pegelolaan penyu belimbing dan pantai peneluran secara partisipatif hal ini telah dijalanakan dengan dibentuknya Forum Kolaborasi Pengelolaan Ekosistem Esensial Pantai Peneluran Jamursba Medi distrik Abun Kabupaten Tambrauw.

Kepedulian terhadap kelestarian, keanekaragaman hayati, peran WWF dalam, monitoring, fasilitasi dan konsultasi untuk mencapai kemajuan dalam mewujudkan visinya 
ekosistem dan keanekaragaman hayati Indonesia terjaga dan dikelola secara berkelanjutan dan merata untuk kesejahteraan generasi sekarang dan yang akan datang.

Program Pendampingan Forum Kolaborasi Pengelolaan Pantai Peneluran Penyu Belimbing, Program status Kawasan Taman Pesisir Jamursba Medi dan Program Pendidikan lingkungan hidup dan keseshatan lingkungan.WWF melakukan kerja sama berkaitan dengan konservasi penyu belimbing dan bentuk kerja sama melalui forum kolaborasi sebagai wadah komunikasi,koordinasi dan singkronissasi para pighak dalam komitmen kegiatan perlindungan penyu belimbing dan pantai penelurannya serta pengembangan masyarakat disekitarnya.

Komitmen untuk saling mendukung antara para pihak untuk upaya konservasi telah diwujudka dengan adanya kegiatan-kegiatan bersama seperti pertemuan rutin Forum Kolaborasi pada setiap dua bulan,melakukan kegiatan turun kampung untuk dengar pendapat bersama masyarakat dan sharing pembiayan untuk kegiatan pelayanana kesehatan, pengembangan kapasitas masyarakat melalui kegiatan kader konservasi dan pelatihan, kunjungan silang ke lokasi konservasi peyu hijau di pantai Pangumbahan Sukabumi, dan mengikuti pertemuan internasional untuk upaya perlindungan Penyu Belimbing di Pasifik.

Program pemberdayaan masyarakat yang telah dilakukan dalam program pemantauan penyu, WWF melibatkan masyarakat sebagai tenaga kerja dan mendapatkan honor yang berlaku sesuai UMR. Pembentukan kelompok masyarakat dalam rangka turut berperan aktif dalam pelestarian dan pemanfaatan sumberdaya yang ada. Antusias masyarakat dalam turut serta berpartisipasi mendukung program tersebut cukup baik. kegiatan pemantauan populasi penyu tampaknya lebih banyak dilakukan oleh lembaga swadaya masyarakat (WWF Indonesia dan Yayasan Alam Lestari dengan mempekerjakan masyarakat lokal. Kegiatan lapangan dilakukan terutama dalam penyediaan informasih ilmiah terkait penyu belimbing.

Kegiatan pemberdayaan masyarakat mulai dilaksanakan dengan cara melibatkan masyarakat sebagai tenaga pemantau pantai, dan pemberian beasiswa pada tahun
2006/2007. Walaupun banyak kendala yang dihadapi namun segala upaya masih terus dilakukan agar tercapai program dan tujuan kerja yang diharapkan WWF Pemerintah dan Masyarakat lokal

\section{d. Peran Pemerintah Daerah}

Peran aktif para pihak pemerintah terkait dalam konservasi Penyu Belimbing (Dermochelys coriacea)terus dilakukan Pemerintah Daerah hingga saat ini, upaya perlindungan dan pengelolaan penyu belimbing serta pantai penelururannya secara kolaboratif dan partisipatif terus upayakanwalaupun belum cukup baik. Salah satu bentunya adalah menggagas Forum Kolaborasi Pengelolaan Ekosistem rEsensial Pantai Peneluran Penyu Belimbing Jamursba Medi dan sekitarnya di Distrik Abun, secara bersama dan Pembentukan Unit Pelaksanaan Teknis Dinas (UPTD) Kawasan Konservasi Penyu Jamursba Medi pada Dinas Kelautan dan Perikanan yang telah di SK-kan oleh Bupati Tambrauw, serta Pencadangan Kawasan Konservasi Taman Pesisir Jamursba Medi dan Laut Sekitarnya oleh Bupati Tambrauw.

Pada kenyataannya Pemerintah Kabupaten Tambrauw dan Balai Besar Konservasi Sumber Daya Alam (BBKSDA) Papua Barat serta anggota Forum Kolaborasi lainnya telah menunjukan keomitmen yang diimplementasikan dalam program nyata walaupun belum maksimal. Komitmen ini dimulai dengan diterbitnya Surat Keputusan (SK) Bupati tambrauw, Tentang Pembentukan Forum Kolaborasi Pengelolaan Ekosistem Marga Satwa Jamursba Medi dan sekitarnya yang terdiri atas 16 anggota. Selanjutnya mengalami perubahan seiring dengan terbitnya SK Bupati Tambrauw Nomor 54 Tahun 2012 tentang pembentukan Forum Kolaborasi Pengelolaan Ekositem Esensial Kawasan Pantai Peneluran Jamursba Medi dan Sekitarnya yang terdiri atas 30 lembaga para pihak yang menjadi anggota.

Adanya forum kolaborasi ini agar memudahkan koordinasi, komunikasi, sinkronisasi, kontribusi pembiayaan serta pembagian peran diantara para pihak dalam upaya konservasi penyu belimbing.

Peran forum kolaborasi ini memiliki harapan yang sesuai dengan pendapat dari Bupati Tambrauw, Gabriel Asem, SE, M.Si yang dikutip "Pengelolaan Kawasan Perlindungan 
Pantai Peneluran Penyu Belimbing harus melibatkan masyarakat dan para pihak lain agar kelestariannya terjaga selaras dengan manfaat ekonomi yang dirasakan oleh masyarakat".

Komitmen saling mendukung antara pihak untuk mengupayakan konservasi satwa ini diwujudkan dengan adanya kegiatan-kegiatan bersama seperti : pertemuan rutin forum kolaborasi setiap bulan, melakukan kegiatan turun kampung untuk dengar pendapat masyarakat, sharingpembiayaan untuk kegiatan yang menunjang program kerja Forum Kolaborasi tersebut.

Pada umumnya ada beberapa instansi terkait yang berperan aktif bersama masyarakat lokal dan lembaga LSM/WWF untuk bekerja sama dalam menunjang program kegiatan konservasi di pantai Peneluran Jamursba Medi seperti Dinas Kehutanan, Perikanan dan Kelautan serta Dinas pariwisata namun pada saat observasi dilapangan tidak ditemukan staf Dinas Kehutanan dan Perikanan sehingga data yang diperoleh hanya dari Dinas Pariwisata Kabupaten Tambrauw.

Peran Dinas Pariwisata Kabupaten Tambrauw dari hasil wawancara bersama Bpk. Safrino D Bame, A.Md, Par Kepala Bidang Promosi bahwa "Kegiatan yang telah dilakukan adalah promosi beberapa kawasan termasuk Pantai Peneluran Jamursba Medi dan beberapa daya tarik wisata lainnya yang berada di kabupaten Tambrauw dan "Sejauh ini sudah ada beberapa upaya yang mau dilakukan dalam rangka menunjang kegiatan konservasi dan Pelestarian Pantai Peneluran Penyu Belimbing namun terdapat beberapa kendala diantara pembiayaan untuk melakukan program dari Dinas Pariwisata itu sendiri, karena setiap sidang anggaran pagu dana yang diberikan kepada Dinas Pariwisata sangat sedikit tidak sesuai permintaan yang diusulkan sehingga banyak program yang tidak dilaksanakan termasuk kegiatan di kawasan Pantai Peneluran Penyu Belimbing yang sebagai salah satu icon kabupaten dan potensi pariwisata bila dikelola dan dikembangkan dengan baik".

Adapun beberapa kegiatan antar negara yang selalu melibatkan Pemerintah Kabupaten Tambrauw untuk ikut berpartisipasi seperti pada kegiatan Pacific Leatherback Sea Turtle Conservation Summit yang diselenggarakan di Monterey, California, USA pada tanggal 14 sampai dengan 16 Oktober 2013 beberapa tahun lalu yang diikut sertakan Bupati Tambrauw beserta Dinas terkait dan WWF untuk peringatan pertama hari konservasi Penyu Belimbing di California dan mengakui pentingnya ekologi serta komitmen bersama untuk upaya memulihkan populaasi Penyu Belimbing yang terancam punah,dan menyatakan niat untuk membangun kemitraan kolaboratif untuk konservasi bersama Penyu Belimbing Pasifik.

\section{SIMPULAN DAN SARAN \\ 5.1 Simpulan}

Pantai Peneluran Penyu Belimbing Jamursba Medi memiliki potensi yang dapat dikembangkan menjadi salah satu daya tarik ekowisata di Kabupaten Tambrauw, karena keunggulan dalam potensi alam, budaya dan manusia, potensi pantainya sebagai tempat bertelurnya Penyu Belimbing jika dikelola dengan baik dapat memberikan dampak ekonomi yang cukup baik kepada masyarakat lokal sekitar kawasan. Upaya yang dilakukan stakeholder pemerintah, masyarakat dan WWF cukup baik pembentukan forum kolaborasi antar instansi-instani terkait dalam rangka kepedulian terhadap kawasan konservasi pantai peneluran jamursba Medi dengan beberapa program kerja namun program yang disepakati bersama tidak dijalankan secara bersama- sama tidak maksimal, tidak adanya koordinasi dan partisipasi antar pemerintah, masyarakat dan WWF, tidak tersedianya sarana dan pra sarana yang memadai, akses menuju lokasi sangat sulitkurangnya dan SDM lokal sangat kurang, belum dikelola sumber daya alam kurangnya promosi pariwisata, kurangnya kepedulian dari pihak pemerintah untuk kawasan pantai peneluran. Beberapa permasalahan ini yang menjadi kendala utama kawasan pantai peneluran Jamursba Medi Kabupaten Tambrauw.

\subsection{Saran}

Agar kawasan pantai peneluran dapatdikembangkan maka beberapa saran yang perlu diperhatikan kapada pihak-pihak terkait dalam upaya pengelolaan kawasan konservasi dan daya tarik ekowisata pantai peneluran Penyu Belimbing Jamursba Medi

1. Potensi yang dimiliki dapat dikembangkan lebih kepada sektor kepariwisataan 
2. Perlu Peningkatan kerja sama antar stakeholder Pemerintah, Masyarakat dan WWF.

3. Perlu adanya perhatian khusus dari instansi terkait untuk meningkatan aksessibilitas sarana dan pra sarana penunjang di kawasan

4. Perlu adanya program peningkatan sumber daya manusia kepada masyarakat lokal disekitar kawasan Pantai Peneluran Jamursba Medi.

\section{DAFTAR PUSTAKA}

Arida, Nyoman Sukma. 2009. Meretas Jalan Ekowisata Bali.Udayana University Press. Denpasar.

Fennel, D.A.1999.ecotourism: An Introduction.Routlege,

Hartati,2002.Peranan WWF Wallacea Terhadap Pelestarian Lingkungan Untuk Pengelolaan Penyu Laut(Skripsi) Program Strata Satu Universitas Pendidikan.

Kusmayadi dan Endar Sugiarto. 2000. Metodologi penelitiaan dalam bidang Kepariwisataan. Jakarta: PT. Gramedia Pustaka Utama.

Pendit, I Nyoman S.1999.Ilmu Pariwisata Sebuah Pengantar Perdana. Jakarta: Pradnya Paramita.

SK Bupati Tambrauw Nomor 46 tahun 2013 Tentang Pencadangan Kawasan Taman Pesisisr Jamursba Medi dan sekitarnya.

Undang-Undang Republik Indonesia No.10. Tahun 2009 Tentang Kepariwisataan

Wiyatnya, Ketut. 2006. Pengembangan Potensi Pantai Batu Sunggu Sebagai Objek Wisata Bahari di Desa Les Kecamatan Tejakula Kabupaten Buleleng. (Skripsi) Program Strata Satu Universitas Udayana.

Wulandari,2002. Pengembangan Potensi Kawasan Air PanasGunungPancar di DesaKarang Tengah KecamatanBabakanKabupaten Bogor.(Skripsi) Program Strata Satu Universitas Udayana.

Yoeti, Oka.A. 1997. Anatomi Pariwisata,Perkembangan Sektor Pariwisata di Indonesia.Bandung; Angkasa. 